\section{Previous Von Hippel Award Winners}

1977

Arthur R. von Hippel

Emeritus Professor,

Massachusetts Institute of Technology

1978

William 0. Baker

Emeritus Chairman of the Board,

Bell Laboratories

1979

David Turnbull

Gordon McKay Professor of Applied

Physics, Harvard University

1980

W. Conyers Herring

Professor of Applied Physics,

Stanford University

1981

James W. Mayer

Francis Norwood Bard Professor of

Materials Science and Engineering,

Cornell University

1982

Clarence M. Zener

Emeritus University Professor,

Carnegie Mellon University

1983

Sir Peter B. Hirsch

Isaac Wolfson Professor of Metallurgy,

University of Oxford

1984

Walter L. Brown

Head of the Radiation Physics

Department, AT\&T Bell Laboratories

1985

John W. Cahn

Senior Fellow, Center of Materials

Science, National Bureau of Standards

1986

Minko Balkanski

Professor of Physics and Director of the

Solid State Physics Laboratory,

Universite Pierre et Marie Curie

\section{MRIS}

\section{Graduate Student Awards Announced for 1987 MRS Fall Meeting}

The Materials Research Society Awards Committee has selected 15 recipients of Graduate Student Awards to be presented at the 1987 Fall Meeting in Boston. The students receive a commemorative plaque, a paid meeting registration fee, and a cash prize. They will be recognized at the Awards Ceremony on Wednesday, December 2, 1987 at 6:00 p.m. in the Grand Ballroom of the Boston Marriott Hotel/Copley Place.

Students were judged on the originality, cogency, quality, and impact of their work in a field related to one or more of the symposia at the 1987 Fall Meeting. The students were also judged on the independence they displayed in their research and on their promise for future accomplishments in materials research.

Listed below are the students who will receive awards and the symposia in which they are participating:

Spiros H. Anastasiadis, Princeton University (Symposium L)

Shaun Clarke, Imperial College, London (Symposia C and D)

Joachim Fröhlingsdorf, University of Cologne (Symposium A)

Gregg Gould, University of North Carolina at Chapel Hill (Symposium F)

Mark William Horn, Pennsylvania State University (Symposia B and $\mathrm{E}$ )

Hyoung-June Kim, Massachusetts Institute of Technology

(Symposium G)

Dennis G. Madeleine, Virginia Polytechnic Institute and State University (Symposium S)

Wen Jin Meng, California Institute of Technology (Symposium D)

Anthony L. Molina, University of North Carolina at Chapel Hill (Symposium M)

Caroline Anne Ross, University of Cambridge (Symposium I)

Jeffrey H. Sanders, Auburn University (Symposium O)

David Vincent Tsu, North Carolina State University (Symposium F)

Lane C. Wilson, Stanford University (Symposium D)

Xin Di Wu, Rutgers University (Symposia AA, A, and B)

Fulin Xiong, California Institute of Technology (Symposia A, B, C, $\mathrm{E}, \mathrm{H}$, and Workshop W) 